\title{
Research on the Precise Support Mechanism for Graduates with Employment Difficulties in the Post-epidemic Era
}

\author{
Huang Yongyin ${ }^{1,}$, Li Huiliang ${ }^{2, \text { b }}$

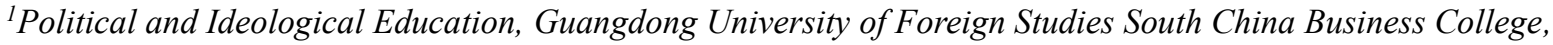 \\ Baiyun District, Guangzhou, China \\ ${ }^{2}$ Political and Ideological Education, Guangdong University of Foreign Studies South China Business College, \\ Baiyun District, Guangzhou, China \\ 1047029902@qq.com \\ b6887774@qq.com
}

\begin{abstract}
At the beginning of 2020, a sudden will coronavirus worldwide, triggered a series of economic and social crisis, many enterprises in the outbreak of the storm declared bankruptcy, and part of the enterprise have to compress the human resources spending, reduce the recruitment, employment market supply decrease greatly, makes that of college graduates employment difficult situation is more serious, therefore, in this paper, starting from the outbreak era this big background, and students from schools, government, and other aspects were discussed, aimed at graduates employment difficult groups helping mechanism, establish and improve the precision order to promote the smooth employment of college students to provide some suggestions.
\end{abstract}

Keywords: Post-epidemic era, employment difficulties, accurate assistance for graduates

\section{后疫情时代就业困难毕业生群体精准帮扶机制研究}

\author{
黄泳茵 ${ }^{1, a}$ 李惠良 ${ }^{2, b}$
}

1 广东外语外贸大学南国商学院思想政治教育，白云区，广州，中国

2 广东外语外贸大学南国商学院思想政治教育，白云区，广州，中国

a1047029902@qq.com

b6887774@qq.com

摘要

2020 年初, 一场突如其来的新冠病毒席卷全球, 引发了一系列经济危机和社会危机, 不少企业在这次疫情风 暴中宣布破产倒闭，还有一部分企业不得不压缩人力资源支出，减少人员招聘，就业供给大大减少，使得原本 就存在的高校毕业生就业困难情况更为严峻, 为此, 本文从后疫情时代这一大背景出发，从学校、政府和学生 本人等多个方面进行探讨, 针对就业困难毕业生群体建立、健全精准帮扶机制, 以促进大学生顺利就业提供一 定参考建议。

关键词: 后疫情时代, 就业困难, 毕业生, 精准帮扶

\section{1. 前言}

自 2020 年初爆发新型冠状病毒疫情以来，受到 防控疫情影响, 各行各业受到了巨大冲击, 不管是小 微企业还是中大型企业, 纷纷选择裁员以控制资金支
出, 各类招聘求职活动普遍推迟, 另一方面, 根据教 育部数据显示, 今年应届毕业生人数创下历史新高, 达到 874 万人, 两者相叠加, 使得今年毕业生的就业 形势异常严峻。 


\section{2. 毕业生群体就业现状及问题}

根据国家统计局数据统计, 1980 年全国普通高 等学校毕业生仅有 14.7 万人, 而 2020 年全国高等学 校毕业生人数突破 800 万, 达 874 万人次, 四十年的 时间, 全国普通高等学校毕业人数翻了将近 60 倍, 中国高等教育发展实现了从精英教育到大众教育的 转变, 用四十年时间走过了其他国家六十年、七十年 甚至更长时间的道路。

但毕业生就业困难问题一直存在, 成为社会关注 的重点, 尤其是受到新冠病毒疫情和经济结构调整双 重影响的 2020 年, 高校毕业生就业形势愈发严峻, 根据 BOSS 直聘发布的《2020 春招就业市场追踪报告》, 报告显示春节后第三周, 面向 2020 年应届生的岗位 需求环比增长 $16 \%$, 但同比仍然下降 $44 \%$, 百人以下 小微企业的应届生需求相比 2019 年收缩了 $52 \%$, 而 今年高校毕业生供给规模的大幅度增加以及受疫情 影响部分行业不景气等因素势必加剧就业的难度。

经过翻阅资料、走访就业部门等方式，笔者整理 统计之后认为当前高等学校毕业生就业主要存在以 下问题:

\section{1 疫情打击企业发展，就业岗位锐减}

新型冠状病毒疫情于 2019 年 12 月底在武汉爆发, 随后扩散到全国大部分地区, 因其极具传染性和爆发 性, 全国上下停业居家抗击疫情, 国内经济活动几近 停滞, 2020 年第一季度 GDP 同比下跌了 $6.8 \%$, 截止 5 月, 2020 年全国企业注销数量已超过 80 万家, 还 呈现出未来持续增加的状态。在这一大背景下, 国内 企业特别是中小企业的生存尤为困难, 为了自保, 大 部分企业纷纷选择调整招聘岗位数量, 或裁员缩招, 以应对上半年疫情停工所带来的严重影响, 今年的高 校毕业生就业出现供求不平衡现象, 企业市场能提供 的就业岗位远远不能满足毕业生就业需求。

\section{2 学生在家养成懒惰习性, 倾向选择“慢就 业”}

因疫情形势严峻不得不在家的高校毕业生, 经历 了最漫长的假期, 无法出门, 无事可做, 每天除了网 课就是吃饭、睡觉、打游戏等, 在紧张、焦虑不安的 氛围之中, 许多毕业生养成了懒惰习性, 不愿就业甚 至抗拒就业。另一方面, 因疫情缘故原本安排在春季 的招聘会推迟到下半年, 学生的应聘计划也因此被延 迟, 使得学生对于原本就不乐观的就业现状更加悲观 沮丧，更多倾向于选择暂缓就业、“慢就业” 以应对 严峻就业形势, 规避就业压力。

\section{3 学校专业课程设计忽略市场需求变化}

随着经济社会的不断向前发展, 我国经济结构逐 渐进入调整转型期, 就业市场对于人才的需求也在动
态变化着, 但我国高校的专业设计仍然停滞不前, 主 要体现在忽视冷门专业建设、专业课程学习缺乏特色, 脱离实际工作等。我国很多高校都会基于市场热门行 业来设置专业, 许多当下最热门的专业每年都会开设 并且师资力量也最充分, 为了吸引生源, 一些高校投 入大量资源开设一系列学习课程相近的类似专业, 而 忽视了冷门专业建设, 这就导致了热门行业人才过剩, 冷门行业人才供给不足的情况发生, 这种情况近几年 也没有得到好转。

另外, 随着社会进步, 企业招聘人才的标准也与 时俱进, 不再一昧看重绩点荣誉, 越发重视学生的实 际应用操作能力, 我们很多毕业生因为在校期间很少 有机会锻炼自己的专业技能和实际应用能力, 导致了 在求职过程中屡屡失败, 实际上, 我国高校所开设的 一些专业课程缺乏专业特色, 教师在课堂上传授理论 知识没有结合实际应用, 教材的知识点落后于现实社 会发展等, 学生选择该专业进行学习并不能为将来的 社会工作提供帮助, 理论知识和实际工作脱节, 这就 导致了一部分大学生一毕业就面临失业。

\section{4 高校招生宣传介绍不充分, 学生盲目选择 专业}

在每一年的招生季当中，高校招生部门都会印制 招生宣传手册、参加各地招生宣讲会等以帮助考生和 家长进行院校和专业选择, 但由于边幅有限、条件限 制等原因, 许多高校在进行招生宣传时没有对各个专 业进行详细介绍说明, 使得众多家长和学生对专业了 解不够深入, 并不清楚这些专业未来的就业方向和前 景, 学生不明确自己的兴趣爱好, 仅凭宣传时的三言 两语便盲目决定自己的大学专业, 这就出现了入学后 学生发现对所学专业不感兴趣或者和想象中不一样 无法坚持学习, 进而递交转专业申请, 但转专业条件 较为苛刻, 并不是所有学生都能成功, 那些未能成功 转专业的学生由于对专业学习兴致不高, 自然无法有 效学习本专业知识和技能, 毕业时难免会出现就业困 难的问题。

\section{5 缺少系统化就业教育指导}

大学生四年都在学校里面生活学习, 对社会的认 知和了解并不多, 为人处世和职场应变能力与社会工 作人士有较大差距, 在求职的过程中容易紧张胆怯, 无法将自己的优势很好地展示给面试官, 造成面试失 败。此外, 在校期间学生对自身未来职业选择非常迷 茫, 缺少系统化的职业规划指导, 对自己选择的企业 和岗位没有明确方向，这也导致了高校毕业生在求职 的时候屡屡碰壁, 影响未来的就业发展。

\section{3. 后疫情时代就业困难毕业生精准帮扶机制}

\section{1 政府方面}

疫情来势汹汹, 全国各行各业都受到严重打击, 
为了引导高校毕业生顺利就业, 国务院联合有关部委 出台了一系列政策文件扶持，如《关于应对新冠肺炎 疫情影响强化稳就业举措的实施意见》, 其中提出了 一些与高校毕业生息息相关的举措, 例如优化自主创 业环境, 加大创业担保贷款支持力度, 免费向高校毕 业生提供一定比例的由政府开发的创业捊化载体; 此 外, 政府还多方式拓宽毕业生就业渠道, 扩大 “三支 一扶” 等基层公共管理岗位, 扩大招生入伍、就业见 习规模, 对录用毕业年度高校毕业生的企业给予补贴 等。

教育部在 2020 年 11 月也发布《教育部关于做好 2021 届全国普通高校毕业生就业创业工作的通知》, 着眼于后疫情时代高校毕业生就业工作, 提出各地教 育部门要推动今明两年的政策性岗位向高校毕业生 倾斜, 促进各类升学和就业工作有序衔接, 鼓励各地 各高校挖掘资源, 以创业带送就业, 拓宽就业空间。 据悉, 2020 年全国专升本考试扩招 32.2 万人, 研究 生考试扩招 18.9 万人。

\section{2 高校方面}

受疫情影响, 传统的高校就业指导工作难以开展, 原本以线下指导为主的高校就业工作部门不得不转 移到线上开展就业指导, 形成线上为主, 线下为辅的 就业帮扶体系。

\subsection{1 加强毕业生心理疏导, 促进心理健康发 展}

年初严峻的疫情形势使得高校毕业生的心理压 力较大, 口罩紧缺、医疗物资匮乏、病毒传染力强等, 使得社会上的恐慌心理加剧, 而高校毕业生本来就面 临着并不乐观的就业形势, 在此氛围下, 心里极容易 产生焦虑、不安等不良情绪。

因此, 高校要注重学生心理疏导, 开通毕业生专 属 24 小时心理咨询热线, 安排专业心理咨询师通过 邮箱、电话、现场谈心等形式, 了解毕业生压力来源, 有针对性进行疏导缓解, 此外, 毕业班级辅导员也要 时刻留意毕业生心理动态, 利用腾讯会议、微信群、 QQ 群等网络平台举行、发布心理疏导小知识, 帮助 毕业生自我判断和自我缓解, 引导毕业生合理寻求外 部帮助, 促进心理健康发展, 更好地应对就业。

\subsection{2 搭建就业信息联动平台，实现资源共享}

出于疫情防控需要, 线下招聘会基本不允许举办, 企业招聘面试由线下转移到线上, 高校就业部门充当 就业单位和求职毕业生的 “牵线员”, 应该及时与网 络招聘平台沟通联系, 了解学生求职动态, 建立毕业 生就业追踪档案, 针对就业困难毕业生实行专档管理, 定点推送招聘信息; 搭建学校专属就业信息联动平台, 在该平台上, 高校就业指导部门联合网络招聘平台发 布企业招聘信息, 毕业生可以通过搜索䇥选功能选择
心仪企业和职位进行在线简历投递，引导企业在联动 平台上举办网络宣讲会、线上双选会、视频面试等, 同时, 在平台上也会设置简历修改、面试辅导、互动 答疑等功能板块, 帮助毕业生解决求职过程中遇到的 常见问题, 实现无缝衔接指导。

\subsection{3 完善在校求职就业指导教育, 形成系统 化辅导}

学生在校期间, 应该系统地学习求职、规划自己 的就业方向, 为此, 高校就业部门应该联合教务处、 学生处等相关部门, 在校内针对毕业生举办就业辅导 培训, 开设电子简历制作修改、视频面试辅导、求职 岗位选择等相关培训课程, 为毕业生提供实实在在的、 具有实际操作性的就业指导。针对非毕业学生, 从大 三开始设置求职规划课程, 由专门的就业指导老师引 导学生为将来的求职意向做好准备和规划, 引导学生 利用寒暑假时间参加公司实习、事业单位见习等, 在 实践中结合理论知识, 了解自己的就业方向和求职意 愿。

\subsection{4 优化专业设置, 提高课堂教学实际应用 水平}

高校应该结合学校实际情况，整理学校开设的专 业和课程, 在充分调研了解市场的人才需求后对学校 专业课程设置进行优化, 撤销一部分相似专业, 避免 出现热门专业扎堆、资源浪费的现象, 集中力量打造 “金牌专业”，提升专业度，对于一些实践能力要求 较高的专业, 可以适当加大实践课程比重, 采取与企 业进行深度校企合作的方式, 打通学生和企业的联系, 企业提供更多实践机会, 使得学生在课堂上就能够了 解企业实际工作, 为将来就业打下坚实的基础。

\subsection{5 加强招生宣传, 详细介绍专业}

高校招生部门在每一年的招生宣传中, 需要采取 多种方式进行专业介绍, 例如专业教师介绍本专业、 招生宣传手册上详细介绍专业学习课程、培养方案、 未来就业方向、专业就业率等, 使学生和家长对专业 的了解更加充分, 解决专业选择的疑惑, 最终选择适 合自己的就业方向, 明确就业目标。

\section{4. 结论}

如今疫情在国内已经得到有效控制, 高校毕业生 就业工作也在稳步推进, 后疫情时代留给毕业生和高 校就业部门的考验还在继续, 只有重视就业困难群体, 提供精准帮扶服务, 才能够有效解决就业困难问题, 实现高校毕业生顺利就业, 平稳度过就业 “寒冬”。

\section{项目基金}

本文为广东外语外贸大学南国商学院 2020 年校 级科研课题立项项目《健全就业困难毕业生群体精准 
帮扶机制研究》(编号：20-011B）成果。

\section{REFERENCES}

[1]. Yue Changjun. The Influence of the Epidemic on the Employment of College Graduates [J]. Employment of Chinese College Students, 2020(06): 4-8.

[2]. Cheng J. The impact of new crown disease on employment and countermeasures [J]. China Development Observation,2020(Z2): 40-42. (in Chinese with English abstract)

[3]. Wang Yang, Wen Zhengjian. Employment of College Graduates under the Epidemic "Great Examination" [J]. Employment of Chinese College Students, 2020(05):14-17.

[4]. ZHOU Dan, LI Dan, YU Wenli. Research on the Path of College Students' Employment Guidance [J]. SME Management and Technology, 2019 (19).

[5]. Fan Bin.On the basis of the practical teaching of ideological and political theory in colleges and universities: Based on the interpretation of the theory of empowerment [J]. Journal of Hubei Correspondence University, 2016 (21).

[6]. Han Ru, Liu Jiandong. Analysis of the employment dilemma of contemporary college students and solutions [J]. Theoretical Observation, 2019(09): $139 \sim 141$. 